\title{
Comparison of the experimentally obtained growth model of Listeria monocytogenes on cucumber and zucchini with existing model generated by ComBase Predictor
}

\author{
Klaudia Szewczuk $^{1} \cdot$ Damian $_{\text {Pietracha }^{1}} \cdot$ Filip Zdziennicki $^{1} \cdot$ Anna Misiewicz $^{1}$
}

Received: 19 August 2015 / Accepted: 3 October 2015 / Published online: 16 October 2015

(C) The Author(s) 2015. This article is published with open access at Springerlink.com

\begin{abstract}
The quality and microbiological safety of produced and stored food is a challenge for its producers and official control. Numerous examples have shown how important it is for them to have access to precise data about the growth time and rate of microorganisms in stored products, especially in the case of those which are the etiology of digestive system diseases such as Listeria monocytogenes. It is one of the most virulent foodborne pathogens, showing a mortality rate of approximately $20-30 \%$, which is the highest among food microbiota. In order to determine the microbial growth kinetics in time on food matrices, socalled growth modeling is used. It allows to determine the growth of microorganisms in time and depending on the temperature, $\mathrm{pH}$, water activity $\left(a_{\mathrm{w}}\right)$, or content of acids. In this paper, we verified the growth model of Listeria monocytogenes on cucumber and zucchini with an existing model in the ComBase Predictor.
\end{abstract}

Keywords Listeria monocytogenes - Cucumber . Zucchini $\cdot$ Growth modeling

\section{Introduction}

Focusing on the microbiological safety of produced and stored food products is a priority for the institutions

Klaudia Szewczuk

klaudia.szewczuk@ibprs.pl

Anna Misiewicz

anna.misiewicz@ibprs.pl

1 Department of Microbiology, Prof. Waclaw Dabrowski Institute of Food and Agriculture Biotechnology, Rakowiecka 36, 02-532 Warsaw, Poland controlling and producing them. Events from a few years ago caused by Listeria monocytogenes detected on cantaloupes, which caused 32 deaths and 1 miscarriage [16] and the recent case of suspected contamination by the same bacteria of sliced apples and withdrawal of entire batches of the product in November 2013 [4] showed how important it is for food producers to have access to precise information about the growth time and growth rate of microorganisms in stored products.

Listeria monocytogenes is one of 19 species of the genus Listeria and the second, next to Listeria ivanovii, showing pathogenic properties [15]. It is a Gram-positive bacillus, which lives intracellularly and is the etiological factor of listeriosis. Bacteria belonging to this species have the highest virulence of all foodborne pathogens (20-30\% of infections are fatal), where the most pathogenic properties were noted for serotype $4 \mathrm{~b}$ [18]. An example of this can be the USA - approximately 2500 cases and 500 deaths per year [5], thereby causing a higher mortality rate than Salmonella sp. or Clostridium botulinum. The main symptoms of listeriosis are septicemia, meningitis, encephalitis, corneal ulcer, pneumonia, and infections of the uterus in pregnant women, which can lead to a miscarriage or intrauterine fetal death $[6,9,10,13,22]$.

Determining the bacterial growth, including Listeria monocytogenes, on different matrices, both fresh and processed, is the role of predictive microbiology. Within it, so-called growth models are formed allowing to determine the growth rate of microorganisms depending on the environmental conditions [20]. The information from modeling is used in the creation of databases, such as the ComBase Predictor (combined database for predictive microbiology), allowing to generate a model based on set variables that have an influence on bacterial growth, such as the $\mathrm{pH}, a_{\mathrm{w}}$, temperature, concentration of $\mathrm{NaCl}[8,14]$. 
The goal of this work was the validation of an existing model in the ComBase Predictor with data obtained experimentally from cucumber and zucchini. The comparison of those results with the predictions allows to verify the reliability of the latter, especially to check whether they retain the necessary safety margin required from the point of view of food producers.

\section{Materials}

The matrices were fresh products of plant origin-zucchini and cucumber, with a $\mathrm{pH}$ of 6.44 and 6.20 , respectively.

For the fortification of the samples, a strain CCIM 1171 of Listeria monocytogenes $4 \mathrm{~b}$ from the culture collection of industrial microorganisms was used.

In this work, Listeria Agar according to Ottaviani and Agosti (ALOA) (Bio-Rad) was used as the culture media, and as the diluent buffered peptone water (BWP) (bioMérieux) and saline with peptone [12].

The growth modeling of Listeria monocytogenes was prepared with DMFit version 2.1., an Excel add-in (Institute of Food Research, Norwich, UK), created by using an algorithm developed by Baranyi and Roberts [1,2].

Growth predictions of the tested microorganisms were generated and downloaded from the ComBase Predictor [3], created by the Food Safety Centre at the Institute of Food Research in the UK.

\section{Methods}

The method of modeling was based on an algorithm made by Baranyi and Roberts [1, 2], whereas the cultures on ISO 11290-2:1998/AM1:2004 [12].

All products were thoroughly washed with water and detergent, in order to mechanically remove any contaminants and microorganisms existing on the surface of the vegetables. Next, the products were immersed in a $70 \%$ aqueous solution of isopropanol for $30 \mathrm{~min}$, taken out and left to dry in a sterile environment.

The vegetables, after the skin had been removed using a sterilized knife, were cut into $10 \mathrm{~g} \pm 1 \mathrm{~g}$ pieces, and then, they were fortified with $0.1 \mathrm{ml}$ of inoculum that contained $10^{5} \mathrm{CFU} / \mathrm{ml}$ of Listeria monocytogenes, the final number amounted to $10^{3} \mathrm{CFU} / \mathrm{g}$ in the sample. Incubation was carried out at a temperature of 4,25 , and $37{ }^{\circ} \mathrm{C}$.

The test was carried out in two repeats and with two dilutions. The number of bacteria in $1 \mathrm{~g}$ or $1 \mathrm{ml}$ was counted according to ISO 7218:2008 [11] in Microsoft Excel.

Thus, obtained data were entered into DMFit, which generated a primary growth model and two parameters validating it: $R^{2}$ is the coefficient of determination, indicating how well data fit the model, and SE(fit), the standard error, is the standard deviation of observed independent variables and growth rate.

To generate the predictive models of Listeria monocytogenes, the ComBase Predictor application was used (Food Safety Centre at the Institute of Food Research, UK).

The growth rate was used to receive the mean square error (MSE).

This value is received from the formula:

$\mathrm{MSE}=\frac{\mathrm{RSS}}{n}=\frac{\sum\left(\mu_{\mathrm{obs}}-\mu_{\mathrm{pred}}\right)^{2}}{n}$

where RSS is the residual sum of squares; $n$ is the number of degrees of freedom/observations; $\mu_{\mathrm{obs}}$ is the observed growth rate $\left(\mathrm{h}^{-1}\right) ; \mu_{\text {pred }}$ is the predicted growth rate $\left(\mathrm{h}^{-1}\right)$.

The lower the value of the MSE, the better the fit of the model [21].

Additionally, graphic validation was used, comprised of a comparison of the predicted and observed growth rate, which allows to preliminarily evaluate the observed results. Their deviation from the so-called equivalence line (eq line) in the direction of the predicted growth indicates that the prediction has a higher growth rate value than the observed growth rate.

Then, the secondary Ratkowsky model was prepared, showing the relationship between the growth rate and temperature. The model was validated with two variables- the bias factor $\left(B_{\mathrm{f}}\right)$ and accuracy factor $\left(A_{\mathrm{f}}\right)$.

The bias factor $\left(B_{\mathrm{f}}\right)$ informs how much a point is deviated from the equivalence line and whether it is above or below it.

$B_{\mathrm{f}}=\exp \left[\frac{\sum\left(\ln \mu_{\mathrm{pred}}-\ln \mu_{\mathrm{obs}}\right)}{n}\right]$

where $n, \mu_{\mathrm{obs}}, \mu_{\text {pred }}$-as above.

When $B_{\mathrm{f}}=1$, it indicates a perfect fit of the model; when $B_{\mathrm{f}}<1$, the observed growth rate is lower than the predicted one, $B_{\mathrm{f}}>1$ indicates a situation recognized as unsafe - the observed growth of microorganisms is faster than the predicted one.

The accuracy factor $\left(A_{\mathrm{f}}\right)$ indicates the average distance between every observed point and the eq line [21].

$A_{f}=\exp \left[\sqrt{\frac{\sum\left(\ln \mu_{\text {pred }}-\ln \mu_{o b s}\right)^{2}}{n}}\right]$

where $n, \mu_{\text {obs }}, \mu_{\text {pred }}$ as above.

When the value of the $A_{\mathrm{f}}$ factor is equal to 2 , it indicates that the observed value differs on average from the prediction by 2 units [21]. 


\section{Results and discussion}

The most effective growth of Listeria monocytogenes was noticed after $24 \mathrm{~h}$ of incubation at 4,25 , and $37^{\circ} \mathrm{C}$ on zucchini (Table 1). A similar amount after $24 \mathrm{~h}$ at $20^{\circ} \mathrm{C}$ was received on papaya by Penteado and Leitao [17]. However, the same authors obtained higher values on watermelon and melon (around $6 \log \mathrm{CFU} / \mathrm{g}$ and $4 \log \mathrm{CFU} / \mathrm{g}$, respectively). At $30{ }^{\circ} \mathrm{C}$, they achieved approximately $7 \log \mathrm{CFU} / \mathrm{g}$ on papaya and $9 \log \mathrm{CFU} / \mathrm{g}$ on watermelon and melon, the naturally created fruit acid did not obstruct the growth of bacteria. The growth of different serotypes of Listeria monocytogenes on cantaloupe was researched by Fang et al. [7]. Serotype $4 \mathrm{~b}$ at $37{ }^{\circ} \mathrm{C}$ reached a value of $9 \log$ $\mathrm{CFU} / \mathrm{g}$.

The results for modeling at $37{ }^{\circ} \mathrm{C}$ for cucumber and zucchini are shown in Figs. 1 and 2.

Based on the analysis of $R^{2}$, it was noted that the most fitted is the value obtained for cucumber at $25^{\circ} \mathrm{C}$ amounting to 0.992838 , and the least is the one for zucchini at $25{ }^{\circ} \mathrm{C}-0.609912$. For cucumber at $4{ }^{\circ} \mathrm{C}, R^{2}$ could not be determined. Similar values, in the range of 0.92-0.96, were obtained by Kowalik et al. [13] and 0.97 by Danyluk et al. [6].

Table 1 Number of Listeria monocytogenes in log CFU/g on zucchini and cucumber after $24 \mathrm{~h}$ of incubation at 4,25 , and $37^{\circ} \mathrm{C}$

\begin{tabular}{llll}
\hline Matrices & \multicolumn{3}{l}{ Temperature } \\
\cline { 2 - 4 } & $4{ }^{\circ} \mathrm{C}$ & $25{ }^{\circ} \mathrm{C}$ & $37{ }^{\circ} \mathrm{C}$ \\
\hline Zucchini & 2.90 & 3.64 & 6.27 \\
Cucumber & 2.88 & 3.19 & 5.02 \\
\hline
\end{tabular}

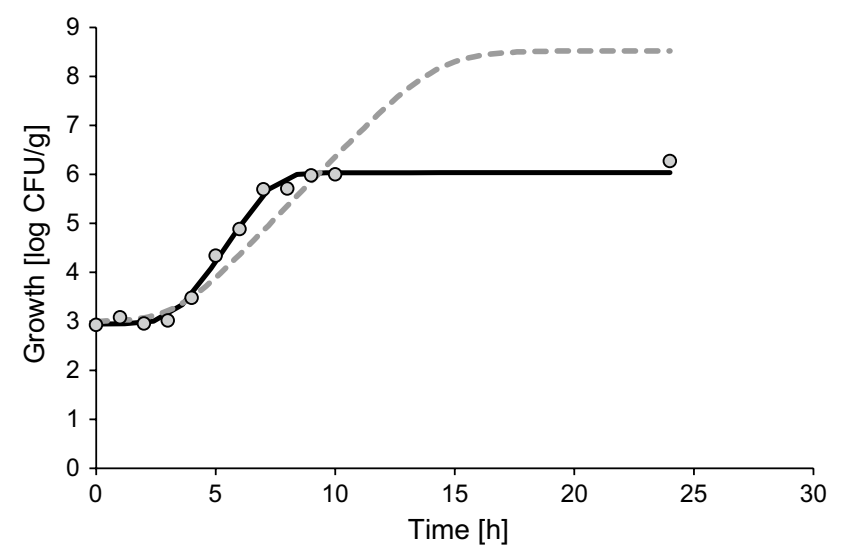

Fig. 1 Results for primary modeling at $37{ }^{\circ} \mathrm{C}$ for zucchini. Circles data obtained experimentally; black line data fitted into a model of Baranyi and Roberts [1, 2]; dotted line data generated by ComBase Predictor

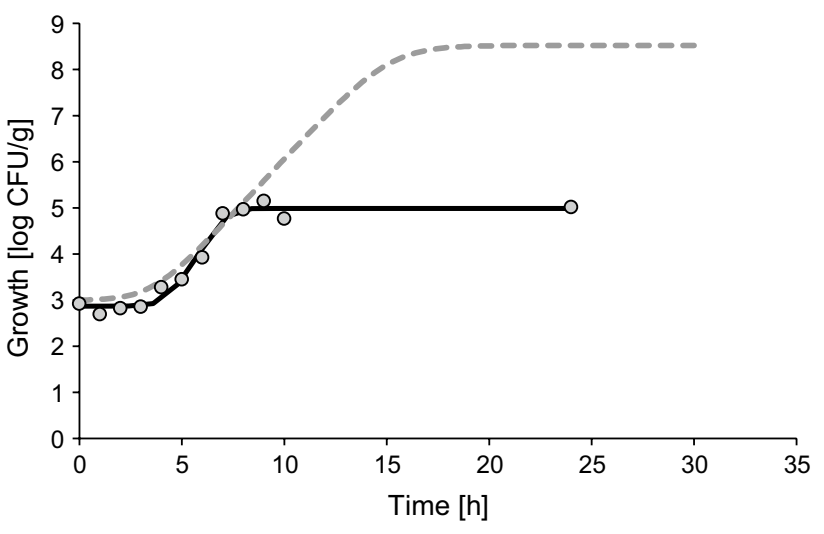

Fig. 2 Results for primary modeling at $37{ }^{\circ} \mathrm{C}$ for cucumber. Circles data obtained experimentally; black line data fitted into a model of Baranyi and Roberts [1, 2]; dotted line data generated by ComBase Predictor

In the case of $\mathrm{SE}$ (fit), the smallest deviation was noted for cucumber at $25{ }^{\circ} \mathrm{C}-0.07268$, and the highest for zucchini at $25{ }^{\circ} \mathrm{C}-0.274805$ and cucumber at $4{ }^{\circ} \mathrm{C}-0.265699$. The highest values were similar to those obtained by Kowalik et al. [13].

The growth rate was the highest for zucchini at $37{ }^{\circ} \mathrm{C}-0.732795\left(\mathrm{~h}^{-1}\right)$, whereas the lowest for cucumber at $4{ }^{\circ} \mathrm{C}-0.000999\left(\mathrm{~h}^{-1}\right)$. The direct connection between the increase in growth rate and the increase in storage temperature was observed, which was confirmed by Kowalik et al. [13], Rodriguez et al. [19].

The results are shown in the Table 2.

The obtained values of growth rate allowed to calculate the MSE for both matrices. The MSE results are as follows: for zucchini- 0.45687 and cucumber- 0.031971 .

The visual representation of the observed growth rate with the predicted growth rate is shown in Figs. 3 and 4.

In the case of zucchini incubated at $4{ }^{\circ} \mathrm{C}$, we are dealing with an ideal situation - the value of the observed growth rate matches the predicted one. There is a similar situation in the case of cucumber incubated at the same temperature. It is different in the case of zucchini and cucumber incubated at $25^{\circ} \mathrm{C}$, where a clear deviation of the value in the direction of the predicted growth rate was observed. It is a favorable situation as the observed growth of microorganisms is slower than the predicted one, leaving a margin of safety, which is preferable for the prediction. An opposite situation has place in the case of zucchini and cucumber incubated at $37{ }^{\circ} \mathrm{C}$, where the observed growth rate is higher than the predicted one. This is a potentially unsafe situation as the microorganisms will continue to develop faster than it is predicted [21].

The growth rate values obtained via DMFit allow to obtain a secondary Ratkowsky model. As it was already mentioned, $A_{\mathrm{f}}$ and $B_{\mathrm{f}}$ factors are used in the validation of this model. 
Table 2 Variables of primary growth model: $\mathrm{R}^{2}$, $\mathrm{SE}$ (fit), growth rate, and lag phase

\begin{tabular}{lclllc}
\hline Matrices & Temperature $\left({ }^{\circ} \mathrm{C}\right)$ & $R^{2}$ & SE(fit) & Growth rate $\left(\mathrm{h}^{-1}\right)$ & Lag phase $(\mathrm{h})$ \\
\hline Zucchini & 4 & 0.836178 & 0.16474 & 0.005385 & - \\
& 25 & 0.609912 & 0.274805 & 0.038756 & - \\
& 37 & 0.988129 & 0.149665 & 0.732795 & 3.274584 \\
Cucumber & 4 & - & 0.265699 & 0.000999 & - \\
& 25 & 0.992838 & 0.07268 & 0.082562 & 22.13034 \\
& 37 & 0.968914 & 0.175599 & 0.685763 & 4.179718 \\
\hline
\end{tabular}

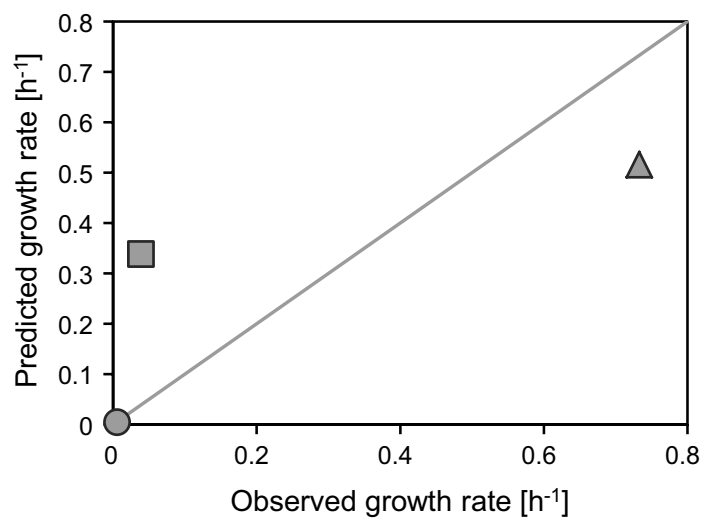

Fig. 3 Comparison of observed and predicted growth rates of Listeria monocytogenes on zucchini. Circles zucchini incubated at $4{ }^{\circ} \mathrm{C}$; square zucchini incubated at $25^{\circ} \mathrm{C}$; triangle zucchini incubated at $37^{\circ} \mathrm{C}$; gray line equivalence line

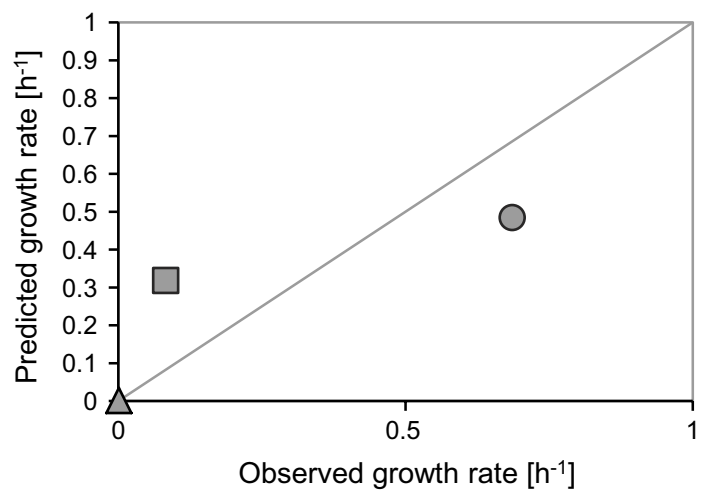

Fig. 4 Comparison of observed and predicted growth rates of Listeria monocytogenes on cucumber. Triangle zucchini incubated at $4{ }^{\circ} \mathrm{C}$; square zucchini incubated at $25^{\circ} \mathrm{C}$; circles zucchini incubated at $37^{\circ} \mathrm{C}$; gray line equivalence line

The shown charts, based on the Ratkowsky model, allow to state that in the case of both matrices, the growth rate increases with the increase in temperature. At a storage temperature of $37{ }^{\circ} \mathrm{C}$, a state noticed during the visual validation of the model is reached-the value of the observed

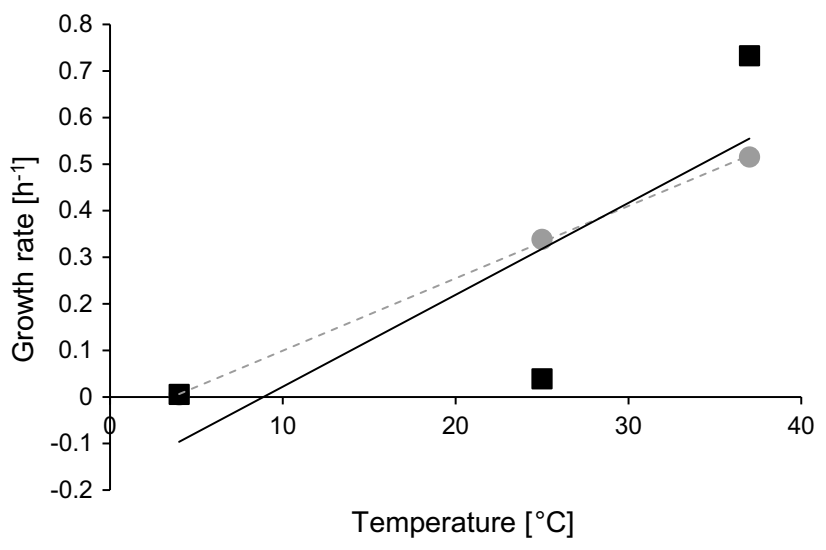

Fig. 5 Result of secondary Ratakowsky modeling for cucumber. Circle predicted growth rate; square observed growth rate

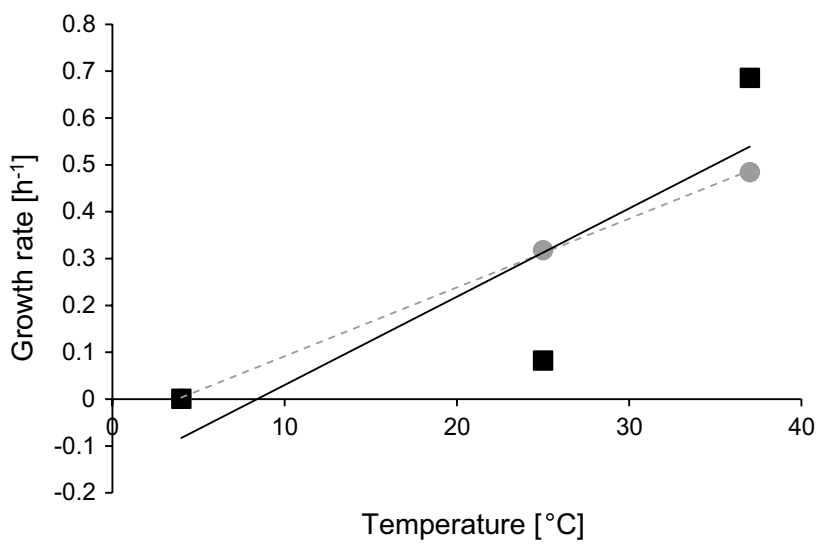

Fig. 6 Results for secondary Ratakowsky modeling for zucchini. Circle predicted growth rate; square observed growth rate

growth rate is higher than the predicted one, this was also observed by other authors [6, 13, 17]. Charts illustrating secondary Ratkowsky modeling are shown in Figs. 5 and 6.

The $A_{\mathrm{f}}$ and $B_{\mathrm{f}}$ values describing this model are shown in Table 3. 
Table 3 Variables of secondary modeling: $A_{\mathrm{f}}$ and $B_{\mathrm{f}}$

\begin{tabular}{lll}
\hline Matrices & $A_{\mathrm{f}}$ & $B_{\mathrm{f}}$ \\
\hline Zucchini & 2.485943 & 1.691753 \\
Cucumber & 2.027171 & 1.503776 \\
\hline
\end{tabular}

In the case of the $A_{\mathrm{f}}$ factor, the lowest values are considered the most precise as this factor indicates by how much the prediction differs from the observed values, so it can be stated that despite the similar values of this factor, the best matched growth model is the cucumber model.

The $B_{\mathrm{f}}$ factor shows the overall deviation of the model. Obtained values higher than 1 are the potentially unsafe models, these also include the models shown here, which confirms the earlier visual analysis of charts.

\section{Conclusion}

Using the growth model of Listeria monocytogenes on zucchini and cucumber, it has been proven that the most beneficial temperature, in which they should be stored, is $4{ }^{\circ} \mathrm{C}$. At the same time, it is suggested to minimize the possibility of their contact with temperatures above $30^{\circ} \mathrm{C}$, because of the observed rapid growth of this pathogen on tested food products.

The obtained results and models show the significance of experimental validations of predictions generated by programmes such as the ComBase Predictor. At this stage, data obtained this way may only be treated as a suggestion and not an incontestable determinant of food product storage. Based on the presented results, it was observed that the yield of Listeria monocytogenes at $37{ }^{\circ} \mathrm{C}$, on both matrices, is a few times higher than the predicted one. It could become a dangerous situation in the future due to a rise in the amount of diseases caused by inaccurate predictions. It is suggested to continue research on the validation of generated data and confront it with that obtained experimentally.

\section{Compliance with ethical standards}

Conflict of interest All the authors declare that there is no conflict of interests regarding the publication of this article.

Compliance with ethics requirements This article does not contain any studies with human or animal subjects.

Open Access This article is distributed under the terms of the Creative Commons Attribution 4.0 International License (http://creativecommons.org/licenses/by/4.0/), which permits unrestricted use, distribution, and reproduction in any medium, provided you give appropriate credit to the original author(s) and the source, provide a link to the Creative Commons license, and indicate if changes were made.

\section{References}

1. Baranyi J, Roberts TA (1994) A dynamic approach to pretending bacterial growth in food. Int J Food Microbiol 23:277-294

2. Baranyi J, Roberts TA (1995) Mathematics of predictive food microbiology. Int J Food Microbiol 26:199-218

3. Baranyi J, Tamplin M(2004)ComBase: a common database on microbial responses to food environments. J Food Prot 67:1834-1840

4. Chakraborty T (1999) Molecular and cell biological aspects of infection by Listeria monocytogenes. Immunobiology 201:155-163

5. Centers for Disease Control and Prevention (CDC) (2012) Multistate outbreak of listeriosis linked to whole cantaloupes from Jensen Farms, Colorado. http://www.cdc.gov/listeria/outbreaks/cantaloupes-jensenfarms/120811/index.html. Accessed 20 May 2015

6. Danyluk MD, Friedrich LM, Schaffner DW (2014) Modeling the growth of Listeria monocytogenes on cut cantaloupe, honeydew and watermelon. Food Microbiol 38:52-55

7. Fang T, Liu Y, Huang L (2013) Growth kinetics of Listeria monocytogenes and spoilage microorganisms in fresh-cut cantaloupe. Food Microbiol 34:174-181

8. Fernandez PS, George SM, Sills ChC, Peck MW (1997) Predictive model of the effect of $\mathrm{CO}_{2}, \mathrm{pH}, \mathrm{NaCl}$ on the growth of Listeria monocytogenes. Int J Food Microbiol 37:37-45

9. Food and Drug Administration (FDA) (2013) Crunch Pak issues voluntary recall of limited quantities of crunch Pak brand apple slices because of possible health risk. http://www.fda.gov/Safety/ Recalls/ucm375135.htm. Accessed 23 Apr 2015

10. Gahan CGM, Hill C (2014) Listeria monocytogenes: survival and adaptation in the gastrointestinal tract. Front Cell Infect Microbiol 4:1-7

11. Hernandez-Milian A, Payeras-Cifre A (2014) What is new in listeriosis? Biomed Res Int. doi:10.1155/2014/358051

12. ISO 7218:2008 Microbiology of food and animal feeding stuffsgeneral requirements and guidance for microbiological examinations

13. ISO 11290-2:1998/AM1:2004 Microbiology of food and animal feeding stuffs-horizontal method for the detection and enumeration of Listeria monocytogenes - part 2: enumeration methodamendment 1: modification of the enumeration medium

14. Kowalik J, Łobacz A, Tarczyńska S (2013) Predicting growth of Listeria monocytogenes cell count in cottage cheese. Food Sci Technol Qual 4:37-48

15. Le Marck Y, Huchet V, Bourgeois CM, Guyonnet JP, Mafart P, Thuault D (2002) Modeling the growth kinetics of Listeria as a function of temperature, $\mathrm{pH}$ and organic acid concentration. Int $\mathrm{J}$ Food Microbiol 73:219-237

16. List of Prokaryotic names with Standing in Nomenclature (LPSN) (2015) Genus Listeria. http://www.bacterio.net/listeria. html. Accessed 06 June 2015

17. Penteado AL, Leitao MFF (2004) Growth of Listeria monocytogenes in melon, watermelon and papaya pulps. Int J Food Microbiol 92:89-94

18. Ramaswamy V, Cresence VM, Rejitha JS, Lekshmi MU, Dharsana KS, Prasad SP, Vijila HM (2007) Listeria-review of epidemiology and pathogenesis. J Microbiol Immunol Infect 40:4-13

19. Rodríguez AMC, Alcalá EB, Gimeno RMG, Cosano GZ (2000) Growth modeling of Listeria monocytogenes in packaged fresh green asparagus. Food Microbiol 17:421-427

20. Szewczuk K, Zdziennicki F, Misiewicz A (2014) The techniques for predicting the growth of Listeria monocytogenes in selected food matrices. Food Ind 11:14-16

21. te Giffel MC, Zwietering MH (1999) Validation of predictive models describing the growth of Listeria monocytogenes. Int $\mathbf{J}$ Food Microbiol 46:135-149

22. Vázquez-Boland JA, Kuhn $\mathrm{M}$, Berche $\mathrm{P}$, Chakraborty $\mathrm{T}$, Domínguez-Bernal G, Goebel W, González-Zorn B, Wehland J, Kreft J (2011) Listeria pathogenesis and molecular virulence determinants. Clin Microbiol Rev 14:584-640 